\title{
S100a8 silencing attenuates inflammation, oxidative stress and apoptosis in BV2 cells induced by oxygen-glucose deprivation and reoxygenation by upregulating GAB1 expression
}

\author{
WENGUANG HU ${ }^{1}$ and CAIMEI LIN ${ }^{2}$ \\ ${ }^{1}$ Pediatric Neurology, Chengdu Women's and Children's Central Hospital, School of Medicine, \\ University of Electronic Science and Technology of China, Chengdu, Sichuan 610091; \\ ${ }^{2}$ Department of Neurology, Xiamen Children's Hospital of Fujian Province, Xiamen, Fujian 361006, P.R. China
}

Received February 10, 2020; Accepted August 11, 2020

DOI: $10.3892 / \mathrm{mmr} .2020 .11702$

\begin{abstract}
S100a8 serves an important role in cell differentiation and is abnormally expressed in common tumors, but there are few studies on the association between S100a8 and brain $\mathrm{I} / \mathrm{R}$ injury. The present study aimed to investigate the role of $\mathrm{S} 100 \mathrm{a} 8$ in oxygen-glucose deprivation and reoxygenation (OGD/R)-induced BV2 microglia cell injury, and to elucidate the potential underlying molecular mechanisms. BV2 cells were exposed to OGD/R to mimic ischemia/reperfusion (I/R) injury in vitro. $\mathrm{S} 100 \mathrm{a} 8$ expression was detected via reverse transcription-quantitative PCR and western blot analyses. Following transfection with short hairpin RNAs targeting S100a8, the levels of inflammatory cytokines and oxidative stress-related factors were determined using commercial kits. Apoptosis was assessed using flow cytometric analysis and the expression levels of apoptosis-related proteins were determined using western blot analysis. Subsequently, the mRNA and protein levels of Grb2-associated binder 1 (GAB1) were assessed following S100a8 silencing. Immunoprecipitation (IP) was performed to verify the association between S100a8 and GAB1. The levels of inflammation, oxidative stress and apoptosis were assessed following GAB1 silencing, along with S100a8 silencing in BV2 cells subjected to OGD/R. The results indicated that exposure to OGD/R markedly upregulated S100a8 expression in BV2 cells. S100a8 silencing inhibited inflammation, oxidative stress and apoptosis, accompanied by changes in the expression of related proteins. The IP assay revealed a strong interaction between GAB1 and S100a8. In addition, GAB1 silencing reversed the inhibitory effects of S100a8 silencing on inflammation, oxidative stress and
\end{abstract}

Correspondence to: Dr Caimei Lin, Department of Neurology, Xiamen Children's Hospital of Fujian Province, 92 Yibin Road, Xiamen, Fujian 361006, P.R. China

E-mail: caimeimoon@163.com

Key words: inflammation, apoptosis, oxygen-glucose deprivation, S100a8, Grb2-associated binder 1 apoptosis in OGD/R-stimulated BV2 cells. Taken together, the results of the present study demonstrated that $\mathrm{S} 100 \mathrm{a} 8$ silencing alleviated inflammation, oxidative stress and the apoptosis of BV2 cells induced by OGD/R, partly by upregulating the expression of GAB1. Thus, these findings may potentially provide a novel direction to develop therapeutic strategies for cerebral I/R injury.

\section{Introduction}

Neonatal hypoxic-ischemic encephalopathy (HIE) refers to the clinical symptoms of hypoxic-ischemic damage to the brain caused by asphyxia during the perinatal period, which is associated with a high morbidity worldwide of $\sim 737$ per 100,000 in 2015 (1-3). Ischemia/reperfusion (I/R)-induced brain injury is one of the most common causes of neonatal brain injury (4). It arises from the temporary interruption of blood supply followed by the recovery of perfusion and concomitant reoxygenation, which exacerbates the dysfunction and leads to damage to the brain parenchyma (5). This disease is life threatening to the newborn and one of the most common causes of neonatal disability affects $\sim 5,000-20,000$ infants per year in Europe (1-4/1,000 live births in high-income countries) and $\sim 1,000,000$ infants per year worldwide $(6,7)$. Although several efforts have been made to determine the underlying mechanisms of cerebral I/R injury, the precise molecular mechanisms remain largely unknown. Thus, a better understanding of the disease is imperative in order to aid the identification of novel targets for the development of effective therapies.

A number of studies have demonstrated that rapid reperfusion possesses the ability to rescue dying cells in ischemic areas; however, it also results in the excessive release of inflammatory mediators and the formation of oxidative stress, which together, contribute to the exacerbation of brain injury $(8,9)$. Increasing evidence suggests that both inflammation and oxidative stress accelerate neuronal apoptosis in the development of cerebral I/R injury $(10,11)$.

S100a8 (also known as calgranulin A or migration inhibitory factor-related protein 8 ) is a member of the S100 protein family of calcium-modulated proteins (12). It is well known that $\mathrm{S} 100 \mathrm{a} 8$ is involved in the pathobiology of inflammatory 
disorders (13). S100a8 is highly expressed in the brains of mice following focal cerebral I/R injury (14). Increasing evidence suggests that $\mathrm{S} 100 \mathrm{a} 8 / \mathrm{a} 9$ genes are significantly upregulated during the early stages of myocardial I/R injury $(15,16)$. Notably, S100a8/a9 plays a vital role in regulating macrophage-mediated renal repair following I/R (17). The Search Tool for the Retrieval of Interacting Genes/Proteins (STRING) http://string-db.org/cgi/input.pldatabase revealed that Grb2-associated binder 1 (GAB1), an intracellular scaffolding adaptor (18), may interact with S100a8 (15). In addition, increasing evidence suggests that GAB1 protects against myocardial I/R injury and oxidative stress in cardiomyocytes $(19,20)$. Activation of the GAB1/Src/ $\beta$-catenin signaling pathway may protect the integrity of the blood-brain barrier following cerebral hemorrhage (21). Thus, the function of $\mathrm{S} 100 \mathrm{a} 8$ in cerebral I/R injury, and whether it can protect against this disease by regulating GAB1 expression, has attracted research interest.

In the present study, oxygen-glucose deprivation and reoxygenation (OGD/R)-induced BV2 cell injury were used to mimic a model of cerebral I/R injury in vitro. The effects of S100a8 on inflammation, oxidative stress and the apoptosis of BV2 cells, and its potential molecular mechanisms were investigated. Taken together, the results of the present study may provide a novel therapeutic target for cerebral I/R injury.

\section{Materials and methods}

Cells and cell culture. The murine microglia cell line, BV2, was provided by the China Center for Type Culture Collection and maintained in Dulbecco's modified Eagle's medium (DMEM; Thermo Fisher Scientific, Inc.) supplemented with $10 \%$ fetal bovine serum (Gibco; Thermo Fisher Scientific, Inc.). BV2 cells were cultured in a $95 \%$ air $/ 5 \% \mathrm{CO}_{2}$ incubator at $37^{\circ} \mathrm{C}$, at saturated humidity.

Prediction of target genes. Search tool for recurring instances of neighboring genes (STRING) database (https://string-db. org/cgi/input.pl; version 11.0) was used. STRING is an open-source platform for studying the miRNA-ncRNA, miRNA-mRNA, ncRNA-RNA, RNA-RNA, RBP-ncRNA and RBP-mRNA interactions from CLIP-seq, degradome-seq and RNA-RNA interactome data.

Cell transfection. Short hairpin (sh)RNAs targeting S100a8 (shRNA-S100a8-1 and shRNA-S100a8-2; $500 \mathrm{ng} / \mu \mathrm{l} ; 50 \mathrm{nmol}$ ), scrambled negative control (NC) shRNA, small interfering (si)RNA against GAB1 and scrambled siRNA-NC were purchased from Shanghai GenePharma Co., Ltd. BV2 cells were seeded into 6-well plates (with DMEM) at a density of $1 \times 10^{6}$ cells/well $24 \mathrm{~h}$ prior to transfection at $37^{\circ} \mathrm{C}$ for $6 \mathrm{~h}$. Lipofectamine ${ }^{\circledR} 3000$ reagent (Invitrogen; Thermo Fisher Scientific, Inc.) was used to perform transfection. Transfection efficiency was assessed using reverse transcription-quantitative (RT-q) PCR and western blot analyses $24 \mathrm{~h}$ post-transfection.

$O G D / R$ treatment. OGD/R was performed to generate $\mathrm{I} / \mathrm{R}$ models in vitro. BV2 cells were seeded into $95-\mathrm{cm}$ cell culture dishes at a density of $1 \times 10^{6}$ cells/well and incubated at $37^{\circ} \mathrm{C}$ for $6 \mathrm{~h}$. To mimic OGD/R injury, cells in the logarithmic growth phase were cultured in glucose-free DMEM and placed in a hypoxic chamber (Thermo Fisher Scientific, Inc.) supplemented with a gas mixture of $1 \% \mathrm{O}_{2}, 94 \% \mathrm{~N}_{2}$ and $5 \% \mathrm{CO}_{2}$ at $37^{\circ} \mathrm{C}$ for $6 \mathrm{~h}$. OGD was terminated by restoration with high-glucose DMEM and incubation under normoxic conditions ( $95 \%$ air and $5 \% \mathrm{CO}_{2}$ ) at $37^{\circ} \mathrm{C}$ for $12 \mathrm{~h}$. BV2 cells without any treatment were used as a control.

Flow cytometric analysis of apoptosis. Apoptosis was detected using an apoptosis detection kit (cat. no. KGA102, Nanjing KeyGen Biotech Co., Ltd.). Following transfection for $24 \mathrm{~h}$, following the manufacturer's manual, BV2 cells were stained with Annexin V-fluorescein isothiocyanate and propidium iodide at room temperature in the dark for $15 \mathrm{~min}$. Apoptosis cells were subsequently analyzed using a flow cytometer (BD Biosciences) and FlowJo software version 7.6.5 (FlowJo LLC).

Immunoprecipitation (IP) assay. BV2 cells $\left(1 \times 10^{7}\right)$ were washed in $2 \mathrm{ml}$ PBS (Beyotime Institute of Biotechnology) and centrifuged at $850 \mathrm{x} \mathrm{g}$ at room temperature for $5 \mathrm{~min}$ to collect the cells. OGD/R-exposed BV2 cells were lysed using lysis buffer for IP (Beyotime Institute of Biotechnology). Lysates were incubated with the indicated antibodies S100a8 (cat. no. 73425; 1:1,000 dilution), GAB-1 (cat. no. 12747; 1:1,000 dilution) and control $\lg \mathrm{G}$ for $1 \mu \mathrm{g}$ plus Protein $\mathrm{A} / \mathrm{G}$ beads (Santa Cruz Biotechnology, Inc.) at $4^{\circ} \mathrm{C}$ for $2 \mathrm{~h}$. The beads were washed with PBS (Beyotime Institute of Biotechnology) three times and the immunoprecipitants were assessed via western blot analysis.

Concentrations of inflammatory cytokines. Culture medium (the supernatant) was collected at the end of the reoxygenation stage. The levels of inflammatory cytokines, including tumor necrosis factor- $\alpha$ (TNF- $\alpha$; cat. no. F11632), interleukin (IL)-1 $\beta$ (cat. no. F10770) and IL-6 (cat. no. F10830) were assessed in the culture supernatant using enzyme linked immunosorbent assay kits (Shanghai Westang Bio-Tech Co., Ltd).

Detection of oxidative stress-related markers. After $12 \mathrm{~h}$ of reoxygenation, the culture supernatant was harvested. The concentration of malondialdehyde (MDA; cat. no. A003-4-1), as well as the activities of superoxide dismutase (SOD; cat. no. A001-3-2) and glutathione peroxidase (GSH-Px; cat. no. A005-1-2) were determined using chemical colorimetric detection kits (Nanjing Jiancheng Bioengineering Institute), according to the manufacturer's instructions.

$R T-q P C R$. Following the different treatments, total RNA was extracted from BV2 cells using TRIzol ${ }^{\circledR}$ reagent (Invitrogen; Thermo Fisher Scientific, Inc.). Total RNA was reverse transcribed into cDNA using PrimeScript RT reagent (Thermo Fisher Scientific, Inc.). Following the manufacturer's protocols, Using SuperScript ${ }^{\mathrm{TM}}$ III Platinum ${ }^{\mathrm{TM}}$ One-Step qRT-PCR kit (Thermo Fisher Scientific, Inc.; cat. no. 11732020) amplification reactions were initially incubated at $94^{\circ} \mathrm{C}$ for $5 \mathrm{~min}$, followed by 35 cycles of $94^{\circ} \mathrm{C} / 30 \mathrm{sec}$, $54^{\circ} \mathrm{C} / 30 \mathrm{sec}$, and $72^{\circ} \mathrm{C} / 20 \mathrm{sec}$ with a final extension at $72^{\circ} \mathrm{C}$ for $2 \mathrm{~min}$. Thermocycling conditions of the qPCR were: $5 \mathrm{~min}$ at $95^{\circ} \mathrm{C}$, with 40 cycles for $30 \mathrm{sec}$ at $95^{\circ} \mathrm{C}$ and $45 \mathrm{sec}$ at $65^{\circ} \mathrm{C}$. Gene expression was quantified using the ABI 7500 
A

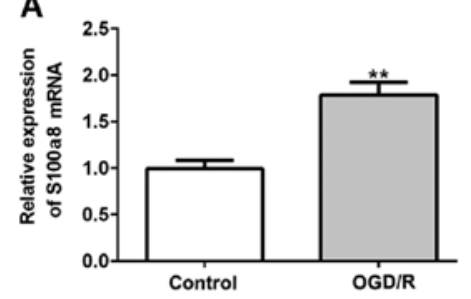

C

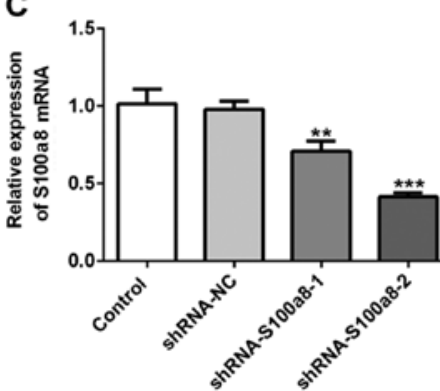

B

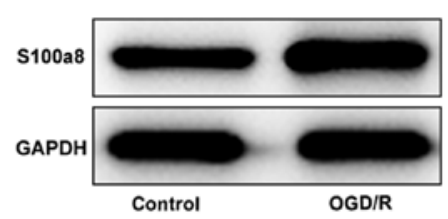

D

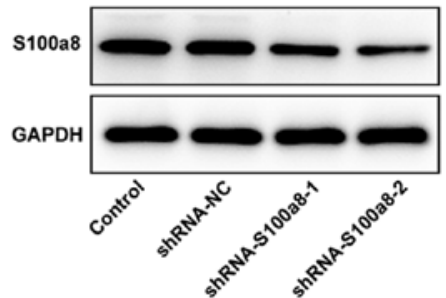

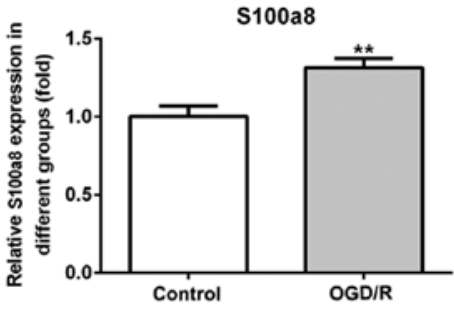

S100a8

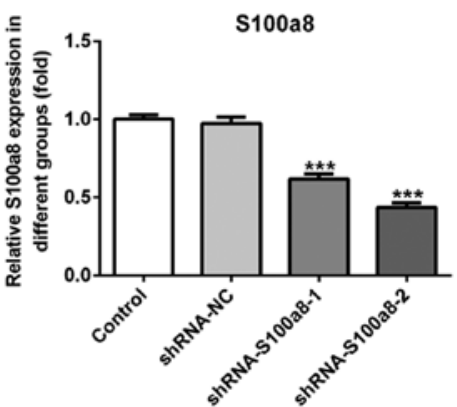

Figure 1. S100a8 is highly expressed in OGD/R-exposed BV2 cells. (A) RT-qPCR and (B) western blot analyses were performed to determine S100a8 expression in BV2 cells following exposure to OGD/R. (C) RT-qPCR and (D) western blot analyses were performed to determine S100a8 expression in BV2 cells following transfection with shRNA-S100a8-1 or shRNA-S100a8-2. ${ }^{* *} \mathrm{P}<0.01$ and ${ }^{* * *} \mathrm{P}<0.001$ vs. the control. OGD/R, oxygen-glucose deprivation and reoxygenation; RT-qPCR, reverse transcription-quantitative PCR; sh, short hairpin; NC, negative control.

PCR system (Applied Biosystems; Thermo Fisher Scientific, Inc.). The following primer sequences were used for qPCR: S100A8 forward, 5'-AAATCACCATGCCCTCTACAAG-3' and reverse, 5'-CCCACTTTTATCACCATCGCAA-3'; GAB1 forward, 5'-GTTGATGCTGGGTTGACATTCA-3' and reverse, 5'-GAAAATCCGGTCGATGGTGTT-3'; cyclooxygenase-2 (COX-2) forward, 5'-ACGGTCCTGAACGCATTT ATG-3' and reverse, 5'-TTGGCCCCATTTAGCAATCTG-3'; induced nitric oxide synthase (iNOS) forward, 5'-CTCTTC GACGACCCAGAAAAC-3' and reverse, 5'-CAAGGC CATGAAGTGAGGCTT-3'; and GAPDH forward, 5'-TTG TCATGGGAGTGAACGAGA-3' and reverse, 5'-CAGGCA GTTGGTGGTACAGG-3'. Relative expression levels were measured using the $2^{-\Delta \Delta \mathrm{Cq}}$ method (22) and normalized to the internal reference gene GAPDH.

Western blotting. Following the different treatments, BV2 cells were collected and total protein was extracted using RIPA buffer (Applygen Technologies, Inc.). Total protein was quantified using the bicinchoninic acid kit (Beyotime Institute of Biotechnology) and $50 \mu \mathrm{g}$ protein/lane was separated via SDS-PAGE and proteins (30 $\mu \mathrm{g} / \mathrm{lane})$ were separated via SDS-PAGE (15\%). The separated proteins were subsequently transferred onto nitrocellulose membranes (EMD Millipore), blocked with $5 \%$ non-fat milk at room temperature for $2 \mathrm{~h}$ and incubated with primary antibodies at $4{ }^{\circ} \mathrm{C}$ overnight against: S100A8 (cat. no. 47310T), GAB1 (cat. no. 3232T), COX-2 (cat. no. 12282T), iNOS (cat. no. 13120S), Src (cat. no. 109381), $\beta$-catenin (cat. no. 32572), Bax (cat. no. 14796S), Bcl-2 (cat. no. 3498T), cleaved caspase-3 (cat. no. 14220T) and GAPDH (cat. no. 5174T), all at 1:1,000 and purchased from Cell Signaling Technology, Inc. Following the primary incubation, the membranes were washed with TBS containing Tween-20 (0.1\%) and incubated at room temperature for $1.5 \mathrm{~h}$ with a horseradish peroxidase-conjugated goat anti-rabbit IgG secondary antibody 1:5,000 (cat. no. SA00001-9, ProteinTech
Group, Inc.) or goat anti-mouse IgG secondary antibody 1:5,000 (cat. no. SA00001-8, ProteinTech Group, Inc.). Protein bands were visualized using the Odyssey Western Blot Analysis system (LI-COR Biosciences) and quantified using ImageJ software version 7.6.5 (National Institutes of Health).

Statistical analysis. All experiments were performed in triplicate and data are presented as the mean \pm standard deviation. Statistical analysis was performed using GraphPad Prism 5 software (GraphPad Software, Inc.) and all data are presented as the mean \pm SEM. Unpaired two-tailed Student's t-test was used to compare differences between two groups, while one-way analysis of variance followed by Tukey's post hoc test was performed to compare differences between multiple groups. $\mathrm{P}<0.05$ was considered to indicate a statistically significant difference.

\section{Results}

S100a8 is highly expressed in OGD/R-exposed BV2 cells. To determine the role of $\mathrm{S} 100 \mathrm{a} 8$ in BV2 cells subjected to OGD/R, RT-qPCR and western blot analyses were performed to detect S100a8 expression. The results demonstrated that S100a8 expression was significantly increased at the transcriptional and post-transcription level following exposure to OGD/R (Fig. 1A and B). Subsequently, shRNA-S100a8-1 or shRNA-S100a8-2 were transfected into BV2 cells, and transfection efficiency was assessed via RT-qPCR and western blot analyses. The results indicated that transfection with shRNA-S100a8-2 decreased S100a8 expression to a greater degree than shRNA-S100a8-1 (Fig. 1C and D). Thus, BV2 cells transfected with shRNA-S100a8-2 were used for subsequent experimentation.

S100a8 silencing inhibits inflammation and oxidative stress in $O G D / R$-exposed BV2 cells. As presented in Fig. 2A-C, exposure to OGD/R significantly increased the contents of inflammatory 

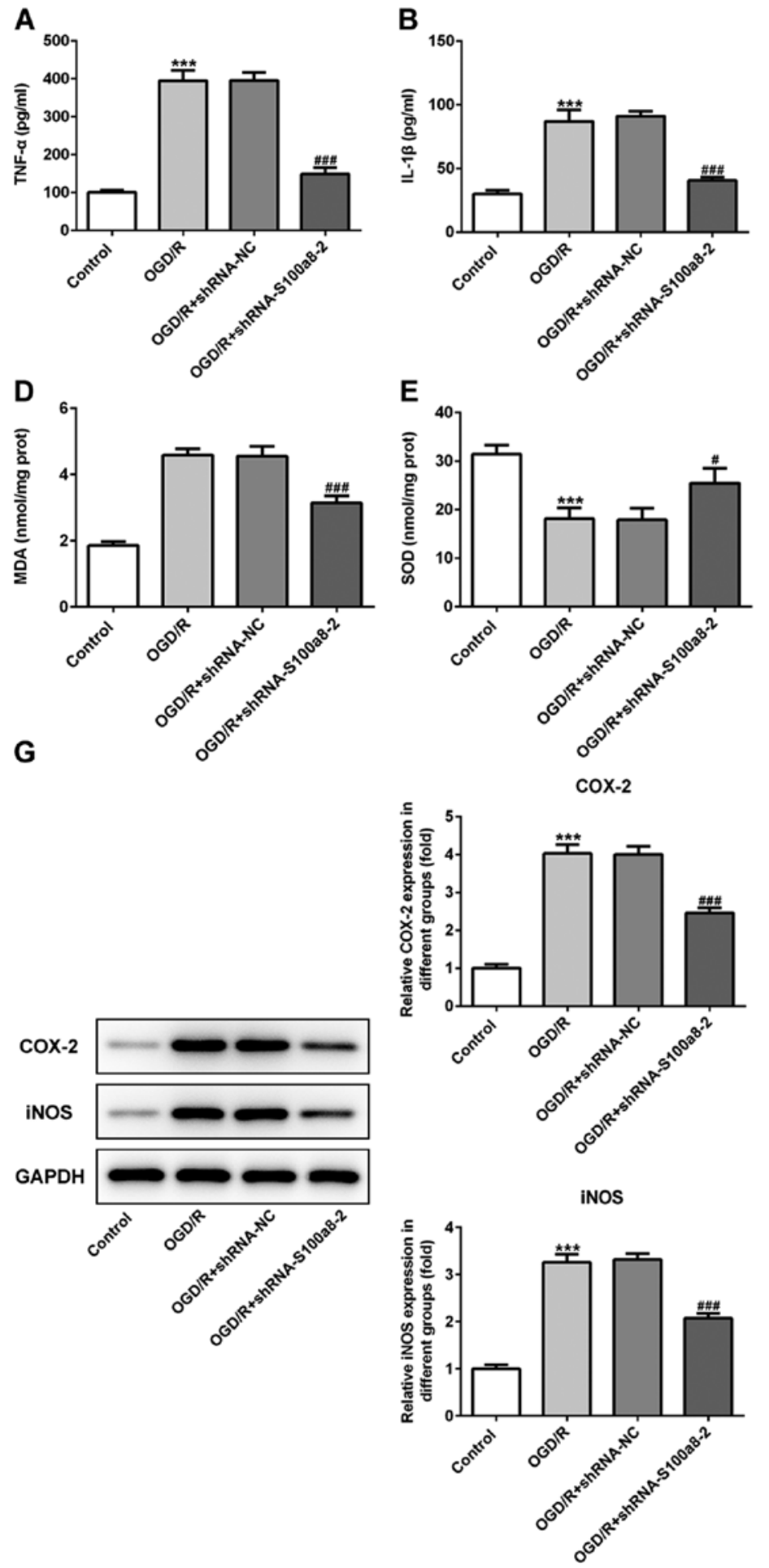
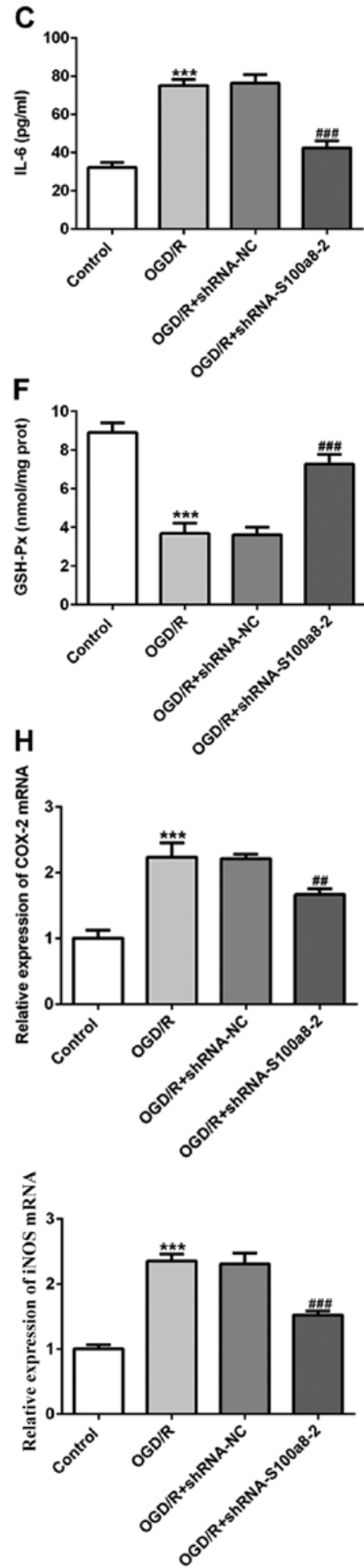

Figure 2. S100a8 silencing suppresses inflammation and oxidative stress in OGD/R-exposed BV2 cells. The expression levels of (A) TNF- $\alpha$, (B) IL-1 $\beta$ and (C) IL-6 were assessed using ELISA kits. The concentration of (D) MDA, as well as the activities of (E) SOD and (F) GSH-Px were determined using commercial kits. (G) Western blot and $(\mathrm{H})$ reverse transcription-quantitative PCR analyses were performed to determine the expression of COX-2 and iNOS following transfection with shRNA-S100a8-2. ${ }^{* * *} \mathrm{P}<0.001$ vs. control; ${ }^{\#} \mathrm{P}<0.05,{ }^{\# \#} \mathrm{P}<0.01,{ }^{\# \# \#} \mathrm{P}<0.001$ vs. OGD/R + shRNA-NC. OGD/R, oxygen-glucose deprivation and reoxygenation; TNF- $\alpha$, tumor necrosis factor $\alpha$; IL, interleukin; MDA, malondialdehyde; SOD, superoxide dismutase; GSH-Px, glutathione peroxidase; COX-2, cyclooxygenase-2; iNOS, induced nitric oxide synthase; sh, short hairpin; NC, negative control.

factors, including TNF- $\alpha$, IL-1 $\beta$ and IL-6, whereas S100a8 silencing inhibited the secretion of the aforementioned factors compared with the NC group. In addition, commercial kits were used to determine the levels of oxidative stress-related markers. The results demonstrated that the concentration of MDA was notably enhanced, accompanied by the decreased activities of SOD and GSH-Px in BV2 cells following exposure to $\mathrm{OGD} / \mathrm{R}$; however, these effects were reversed following transfection with siRNA-S100a8-2 (Fig. 2D-F). To determine the potential underlying molecular mechanisms, the expression levels of COX-2 and iNOS were assessed via western blot and RT-qPCR analyses, respectively. The results 
A

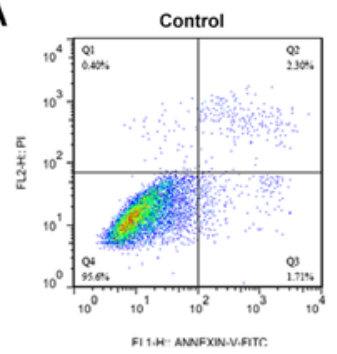

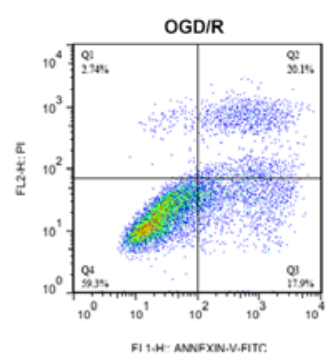

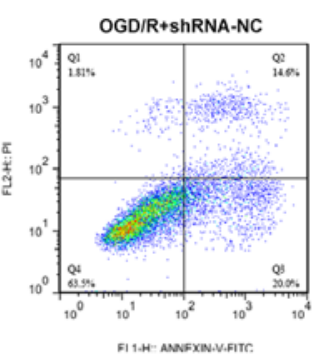

B
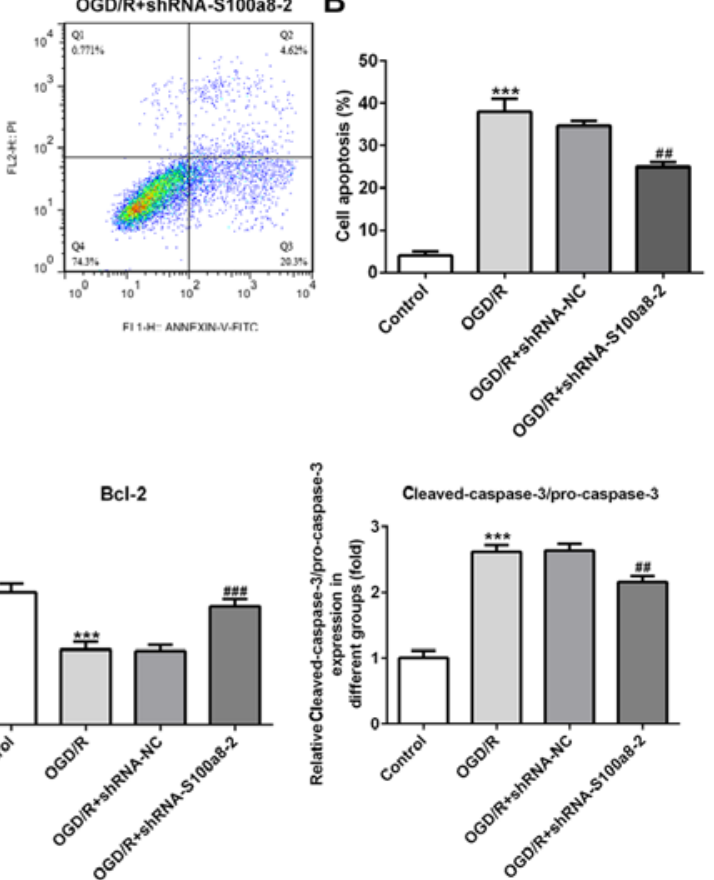

Bcl-2
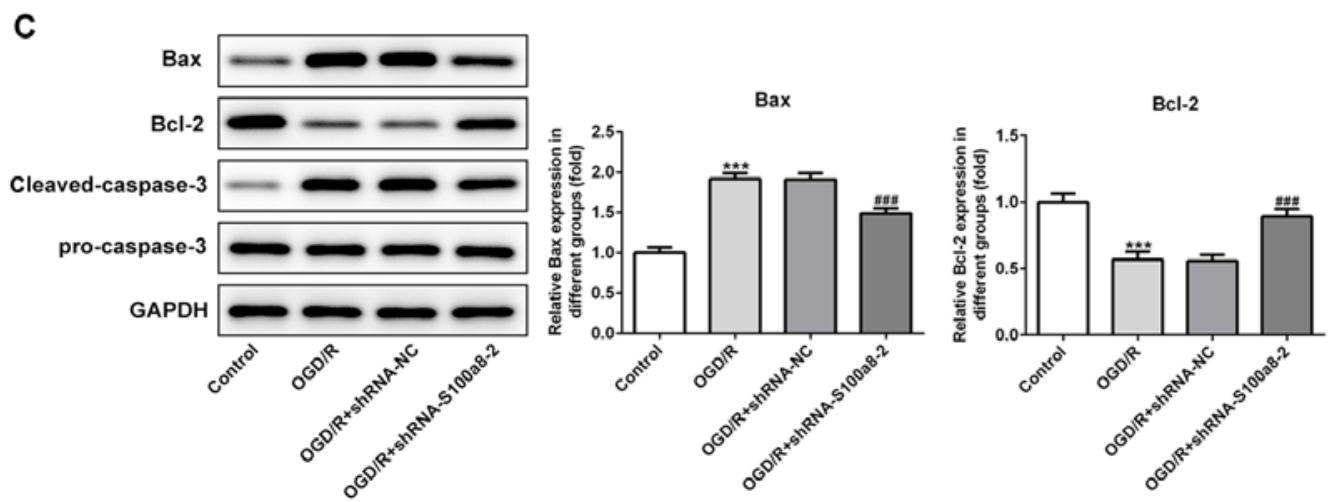

Figure 3. S100a8 silencing restrains apoptosis in OGD/R-exposed BV2 cells. (A) Apoptosis of BV2 cells was assessed via flow cytometric analysis. (B) Quantifications of apoptotic rate. (C) Expression of apoptosis-related proteins was assessed via western blot analysis. ${ }^{* * *} \mathrm{P}<0.001$ vs. control; ${ }^{\# \#} \mathrm{P}<0.01$,

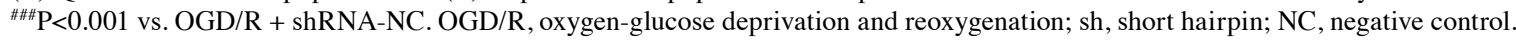
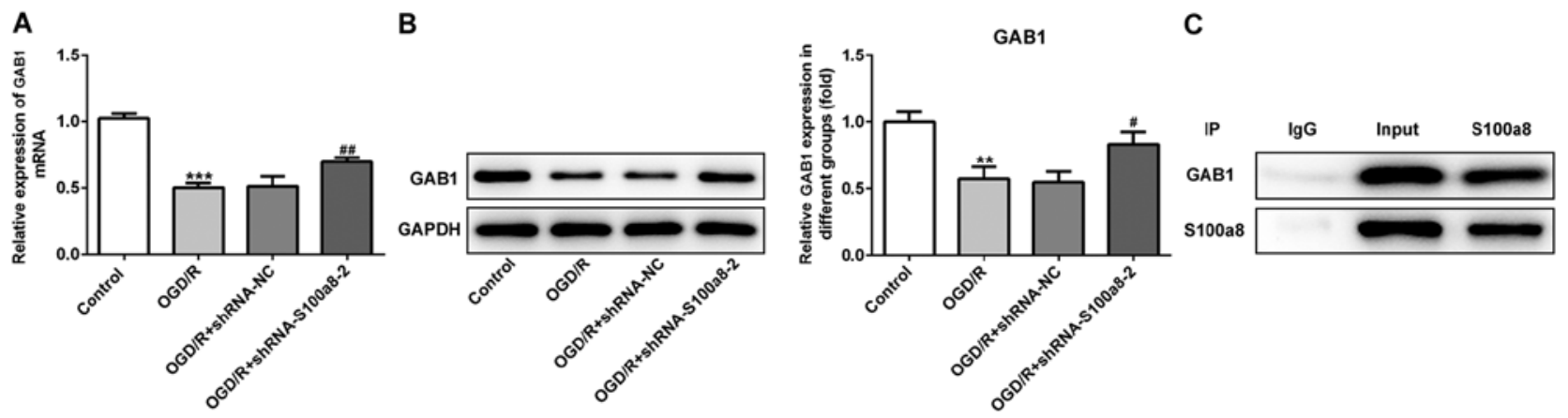

Figure 4. GAB1 directly interacts with S100a8. (A) Reverse transcription-quantitative PCR and (B) western blot analyses were performed to determine GAB1 expression following transfection with shRNA-S100a8-2. (C) IP was performed in BV2 cells and the immunocomplexes were subjected to western blot analysis. ${ }^{* *} \mathrm{P}<0.01,{ }^{* * *} \mathrm{P}<0.001$ vs. control; ${ }^{\#} \mathrm{P}<0.05$, ${ }^{\# \#} \mathrm{P}<0.01$ vs. OGD/R + shRNA-NC. OGD/R, oxygen-glucose deprivation and reoxygenation; GAB1, Grb2-associated binder 1; sh, short hairpin; NC, negative control; IP, immunoprecipitation.

demonstrated that COX-2 and iNOS expression were markedly upregulated in the OGD/R group compared with the control group, whereas S100a8 silencing downregulated COX-2 and iNOS expression (Fig. 2G and H). Taken together, these results suggest that $\mathrm{S} 100 \mathrm{a} 8$ silencing suppresses inflammation and oxidative stress in OGD/R-exposed BV2 cells.

S100a8 silencing restrains apoptosis in OGD/R-induced $B V 2$ cells. To investigate the function of S100a8 silencing on the apoptosis of OGD/R-exposed BV2 cells, flow cytometric analysis was performed to detect the apoptotic rate. The results demonstrated that exposure to OGD/R markedly enhanced the apoptotic rate of BV2 cells relative to the control group, whereas S100a8 silencing decreased cell apoptosis (Fig. 3A and B). Consistently, the expression levels of the pro-apoptotic proteins, Bax and cleaved-caspase-3/pro-caspase-3, were notably upregulated accompanied by downregulated expression of the anti-apoptotic protein, Bcl-2, following OGD/R stimulation; however, these effects were reversed following transfection with shRNA-S100a8-2 (Fig. 3C). Collectively, these results suggest that $\mathrm{S} 100 \mathrm{a} 8$ silencing inhibits the apoptosis of BV2 cells subjected to OGD/R.

GAB1 directly interacts with S100a8. To further determine the molecular mechanisms underlying S100a8-mediated inflammation, oxidative stress and the apoptosis of OGD/R-exposed BV2 cells, the STRING database was used to predict the potential proteins interacting with S100a8. The results indicated that GAB1 directly interacts with S100a8. As presented in Fig. 4A and B, GAB1 expression markedly decreased in the OGD/R-exposed group compared with the NC group, while S100a8 silencing evidently increased GAB1 expression 

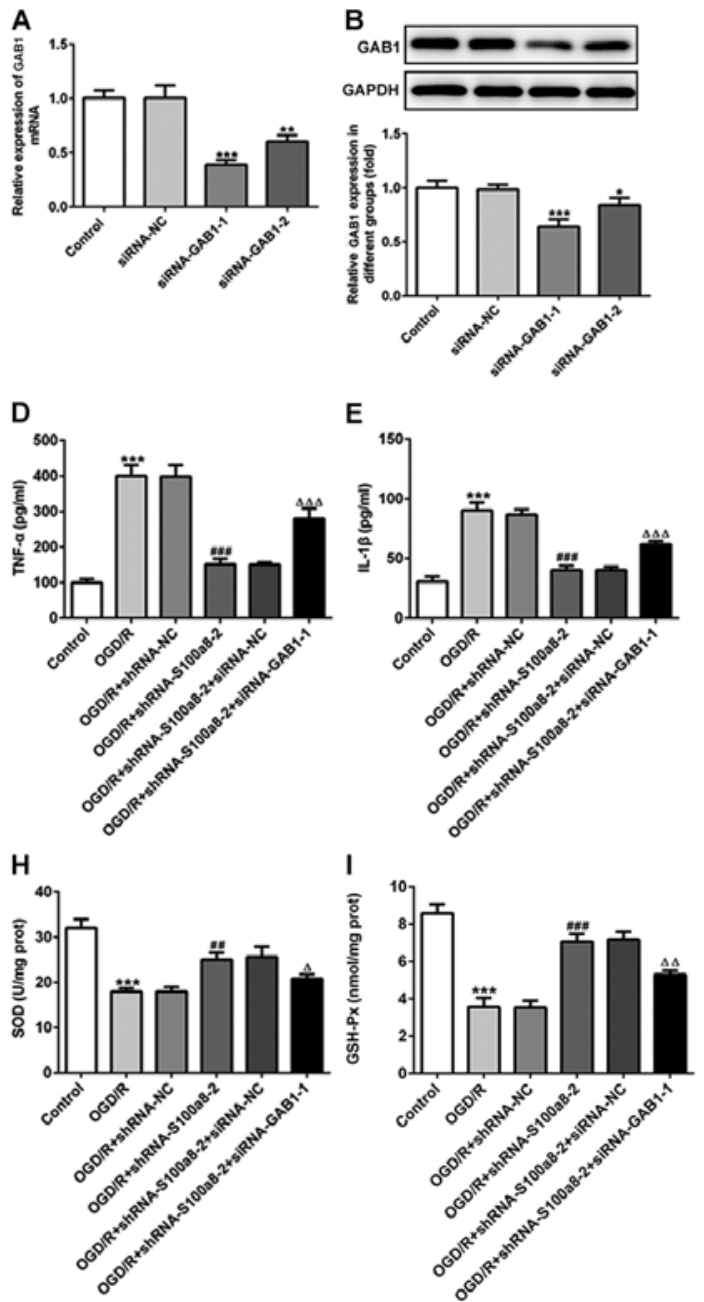
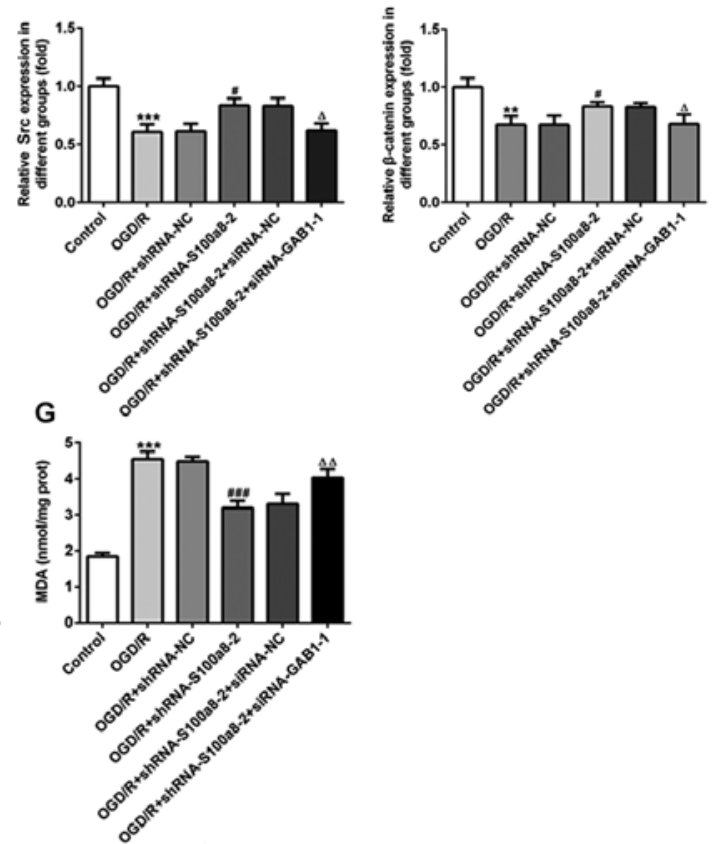

$J$

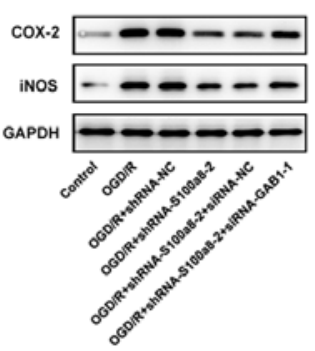

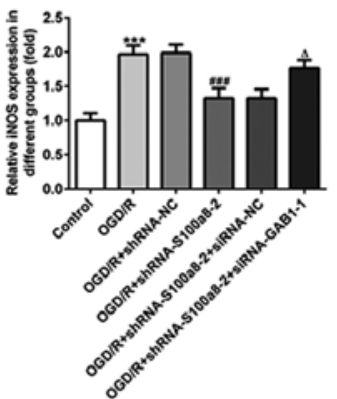
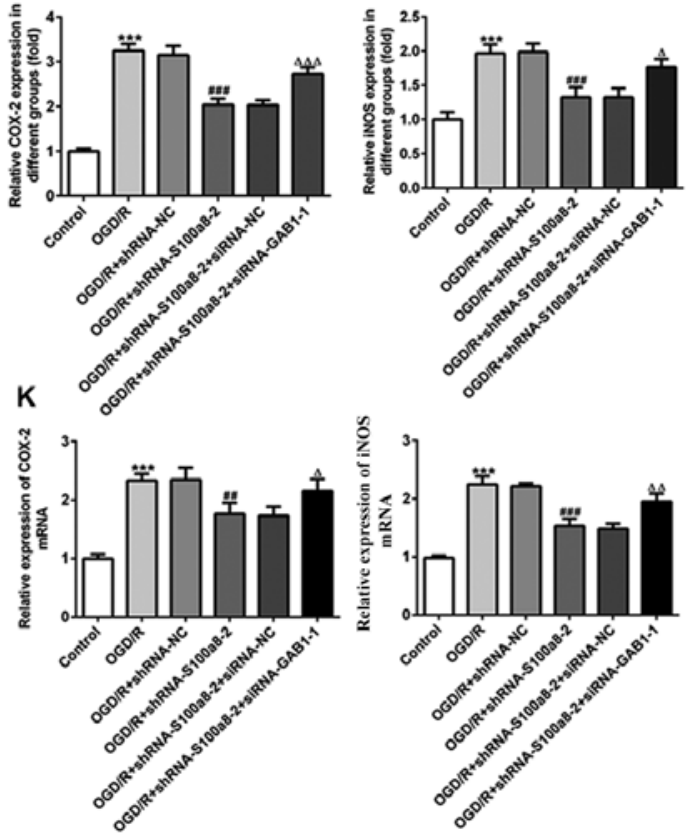

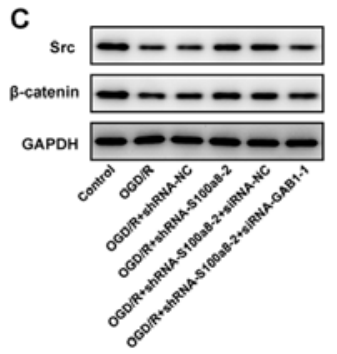

F

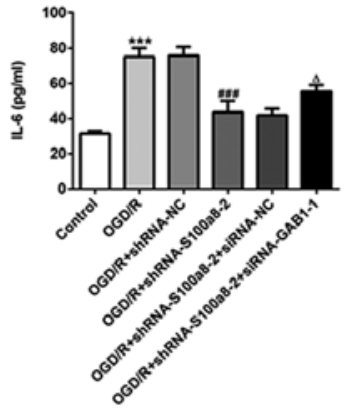

Figure 5. GAB1 silencing alleviates the inhibitory effects of S100a8 silencing on inflammation and oxidative stress in OGD/R-exposed BV2 cells. (A) RT-qPCR and (B) western blot analyses were performed to determine GAB1 expression following transfection with siRNA-GAB1-1 or siRNA-GAB1-2. (C) Expression of downstream targets of GAB1, including Src and $\beta$-catenin was assessed via western blot analysis. Expression levels of (D) TNF- $\alpha$, (E) IL-1 $\beta$ and (F) IL-6 were determined using ELISA kits. The concentration of (G) MDA, as well as the activities of (H) SOD and (I) GSH-Px were determined using commercial kits. (J) Western blot and (K) RT-qPCR analyses were performed to determine the expression levels of COX-2 and iNOS. ${ }^{*} \mathrm{P}<0.05,{ }^{* * *} \mathrm{P}<0.01,{ }^{* * *} \mathrm{P}<0.001$

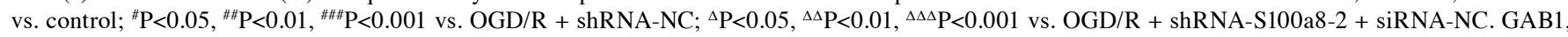
Grb2-associated binder 1; OGD/R, oxygen-glucose deprivation and reoxygenation; RT-qPCR, reverse transcription-quantitative PCR; si, small interfering; TNF- $\alpha$, tumor necrosis factor $\alpha$; IL, interleukin; MDA, malondialdehyde; SOD, superoxide dismutase; GSH-Px, glutathione peroxidase; COX-2, cyclooxygenase-2; iNOS, induced nitric oxide synthase; sh, short hairpin; NC, negative control.

compared with the OGD/R-exposed group. The IP assay confirmed a strong association between GAB1 and S100a8 (Fig. 4C). Taken together, these results suggest that GAB1 can directly interact with $\mathrm{S} 100 \mathrm{a} 8$ in $\mathrm{OGD} / \mathrm{R}$-exposed BV2 cells.

GAB1 silencing alleviates the inhibitory effects of S100a8 silencing on inflammation and oxidative stress in $O G D / R$ exposed BV2 cells. siRNA-GAB1-1 or siRNA-GAB1-2 were transfected into BV2 cells and GAB1 expression was determined (Fig. 5A and B). The results demonstrated that GAB1 expression was significantly downregulated following transfection, and that transfection with siRNA-GAB1-1 decreased GAB1 expression compared with the control group. Thus, BV2 cells transfected with siRNA-GAB1-1 were used for subsequent experimentation. The expression of downstream targets of GAB1, including Src and $\beta$-catenin was assessed via western blot analysis. Exposure to OGD/R significantly downregulated the expression of both Src and $\beta$-catenin compared 

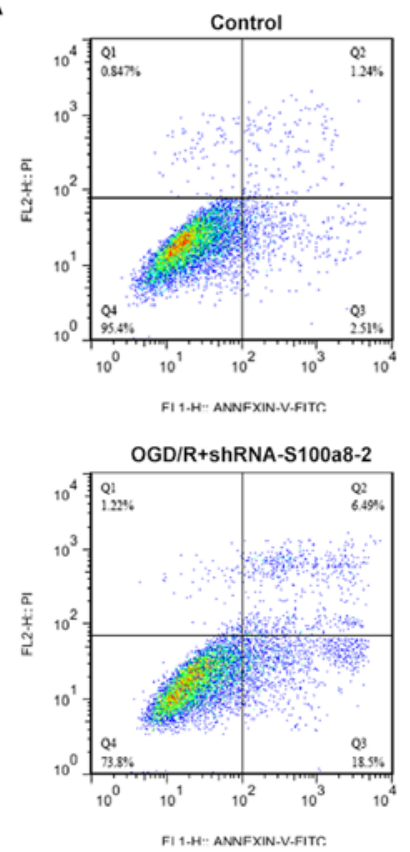

C

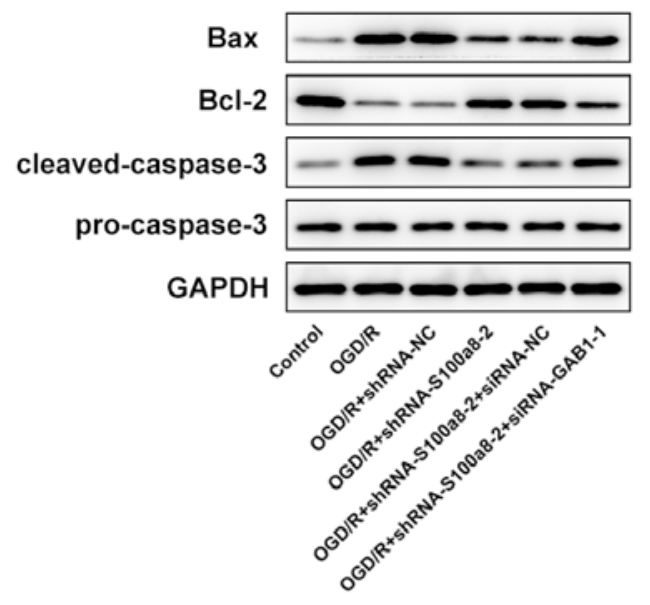

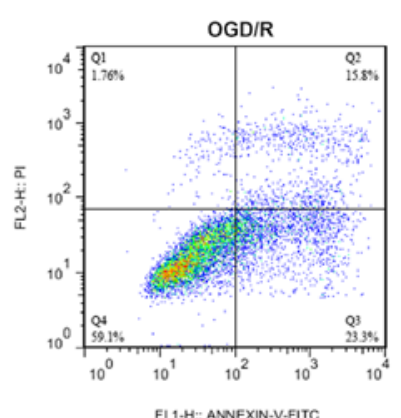

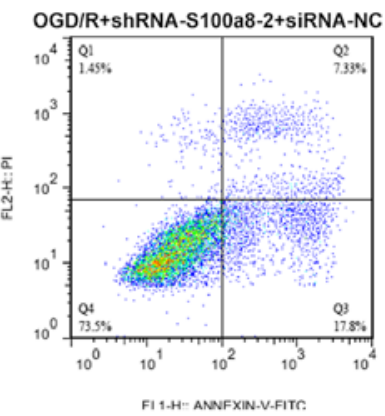

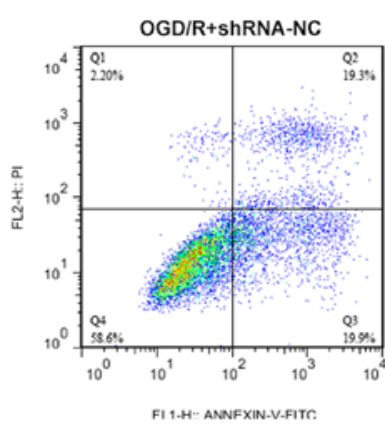

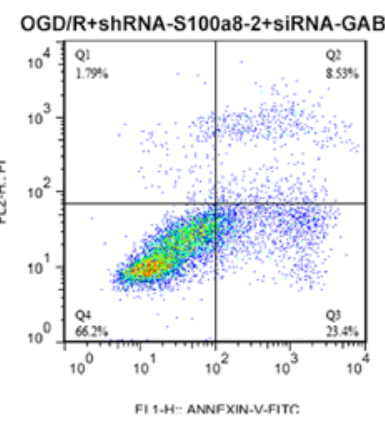

Bax
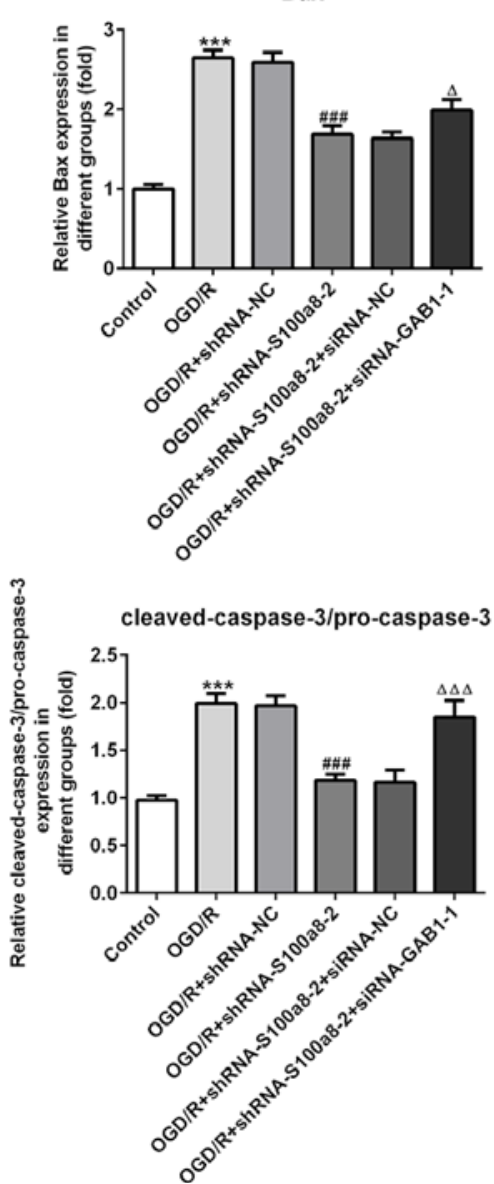

B

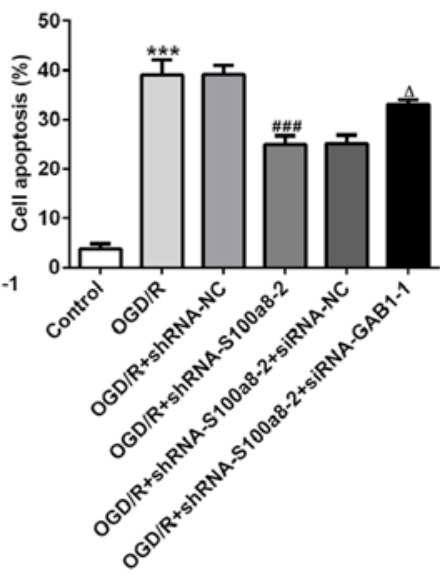

Bcl-2

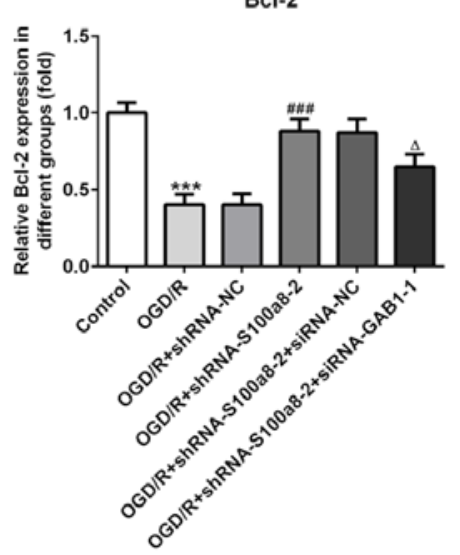

Figure 6. GAB1 silencing abrogates the inhibitory effects of S100a8 silencing on the apoptosis of OGD/R-exposed BV2 cells. (A) Apoptosis of BV2 cells was assessed via flow cytometric analysis. (B) Quantifications of apoptotic rate. (C) The expression of apoptosis-related proteins was assessed via western blot analysis. ${ }^{* * * *} \mathrm{P}<0.001$ vs. the control; ${ }^{\# \# \#} \mathrm{P}<0.001$ vs. OGD/R + shRNA-NC; ${ }^{\Delta} \mathrm{P}<0.05,{ }^{\Delta \Delta \Delta} \mathrm{P}<0.001$ vs. OGD/R + shRNA-S100a8-2 + siRNA-NC. GAB1, Grb2-associated binder 1; OGD/R, oxygen-glucose deprivation and reoxygenation; sh, short hairpin; NC, negative control; si, small interfering.

with the control, while S100a8 silencing evidently increased their expression compared with the NC group (Fig. 5C). However, GAB1 silencing restored the inhibitory effects of
S100a8 silencing on the expression levels of Src and $\beta$-catenin (Fig. 5C). In addition, as presented in Fig. 5D-F, GAB1 silencing enhanced the expression levels of TNF- $\alpha$, IL- $1 \beta$ and 
IL-6 relative to the siRNA-NC group in the OGD/R-exposed BV2 cells, along with S100a8 silencing. Simultaneously, GAB1 silencing attenuated the effects of S100a8 silencing on the level of MDA and the activities of SOD and GSH-Px (Fig. 5G-I). As expected, the expression levels of COX-2 and iNOS markedly increased following silencing of GAB1 and S100a 8 compared with S100a8 silencing alone (Fig. 5J and K). Collectively, these results indicate that GAB1 silencing abrogates the inhibitory effects of S100a8 silencing on inflammation and oxidative stress in OGD/R-exposed BV2 cells.

GAB1 silencing blocks the inhibitory effects of S100a8 silencing on the apoptosis of $O G D / R$-exposed BV2 cells. The results demonstrated that silencing of GAB1 and S100a8 promoted the apoptosis of BV2 cells induced by $\mathrm{OGD} / \mathrm{R}$ compared with S100a8 silencing alone (Fig. 6A and B). In addition, the expression levels of Bax and cleaved-caspase-3/pro-caspase-3 decreased, coupled with an evident increase in Bcl-2 expression following S100a8 silencing, which was abrogated following transfection with shRNA-S100a8-2 and siRNA-GAB1-1 (Fig. 6C). Taken together, these results suggest that GAB1 silencing blocks the inhibitory effects of S100a8 silencing on the apoptosis of OGD/R-exposed BV2 cells.

\section{Discussion}

Cerebral I/R injury is one of the most common causes of neonatal brain injury about 1 million or $23 \%$ of newborn deaths worldwide every year $(23,24)$. It arises from the temporary interruption of blood supply followed by the recovery of perfusion and concomitant reoxygenation, whereby reperfusion induces neuronal injury in the brain (25). Neuroinflammation and neuronal apoptosis have been reported to be notably increased in the processes of $I / R$, both of which have been confirmed to play crucial roles in I/R-induced neuronal damage (26) The results of the present study indicated that S100a8 was highly expressed in OGD/R-exposed BV2 cells. Furthermore, S100a8 silencing attenuated OGD/R-induced inflammation, oxidative stress and the apoptosis of BV2 cells by upregulating GAB1 expression.

It is well-known that inflammation and oxidative stress are closely associated with the progression of I/R-induced multiple organ injury (27-29). Increasing evidence suggests that inflammation is largely caused by microglia that release cytotoxicity or pre-inflammatory markers, including TNF-a, IL-1 $\beta$, IL-6, COX-2 and iNOS (30-32). The excessive production of reactive oxygen species (ROS) results in the imbalance of oxidation and antioxidants in organisms, which plays a catalytic role in the progression of cerebral I/R injury (33). MDA, the end product of lipid peroxidation induced by ROS during oxidative stress, causes oxidative damage by destroying multiple biomacromolecules in biological membranes or organelles, such as lipids, enzymes and nucleic acids $(34,35)$. In addition, SOD and GSH-Px, important antioxidant enzymes, can suppress and attenuate brain tissue injury induced by ROS cytotoxicity during I/R (36). Previous studies have highlighted the importance of S100a8 in the pathobiology of inflammatory disorders $(11,37,38)$. Treatment with S100a8/a9 has been demonstrated to markedly increase the secretion of the aforementioned pro-inflammatory cytokines in cultured BV2 microglial cells (14). Notably, S100A8 induces cytokine expression via the ROS-dependent activation of NF- $\kappa B$ (39). A previous study reported that $\mathrm{S} 100 \mathrm{a} 8$ is highly expressed in the brains of mice following focal cerebral I/R (25). The results of the present study demonstrated that S100a8 was highly expressed in OGD/R-exposed BV2 cells. In addition, S100a8 silencing notably decreased the expression levels of inflammatory markers, decreased the content of MDA and increased the activities of SOD and GSH-Px in OGD/R-stimulated BV2 cells. Collectively, the results of the present study demonstrated that S100a8-knockdown can effectively attenuate OGD/R-induced BV2 cell injury by suppressing inflammation and oxidative stress.

Apoptosis is one of the main forms of cell death following cerebral I/R (40). Increasing evidence indicates that inflammation and oxidative stress contribute to the apoptosis of microglia in the development of brain injury induced by $\mathrm{I} / \mathrm{R}(41,42)$. Caspase- 3 , a member of the caspase family, is one of the key proteins that dominates the apoptotic pathway (43). The activated expression of caspase-3, considered the 'golden' index for the detection of apoptosis, can result in a cascade of apoptotic reactions (44). Bcl-2 family members also play an important role in the regulation of apoptosis (45). The $\mathrm{Bcl}-2$ family is composed of antiapoptotic and proapoptotic proteins, and Bcl-2 and Bax are the two crucial proteins during apoptosis (46). Increasing evidence suggests that S100a8 can induce apoptosis in several cells of different origins such as skin and cancer cells (47-49). Consistent with previous findings $(50,51)$, the results of the present study indicated markedly downregulated expression of the proapoptotic proteins, Bax and cleaved-caspase-3/pro-caspase-3, and upregulated expression of the antiapoptotic protein, Bcl-2, following S100a8 silencing and OGD/R exposure in BV2 cells, respectively. Taken together, these results suggest that $\mathrm{S} 100 \mathrm{a} 8$ silencing suppresses the apoptosis of OGD/R-exposed BV2 cells.

The STRING database revealed that GAB1 interacts with S100a8. Increasing evidence indicates that GAB1 protects cardiomyocytes against myocardial I/R injury and oxidative stress (15). The absence of GAB1 in endothelial cells can accelerate angiotensin II-dependent vascular inflammation and aortic atherosclerosis (52). Additionally, activation of the GAB1/Src/ $\beta$-catenin signaling pathway can protect the integrity of the blood-brain barrier following cerebral hemorrhage (21). The results of the present study demonstrated that S100a8 silencing increased GAB1 expression in BV2 cells exposed to $\mathrm{OGD} / \mathrm{R}$. In addition, the IP assay confirmed that there was a strong association between GAB1 and S100a8. Notably, GAB1-knockdown reversed the effects of S100a8 silencing on inflammation, oxidative stress and apoptosis. Collectively, these results suggest that S100a8 silencing can attenuate OGD/R-induced BV2 cell injury by regulating GAB1 expression.

In conclusion, the results of the present study demonstrate that S100a8 silencing alleviates inflammation, oxidative stress and the apoptosis of BV2 cells induced by OGD/R by upregulating GAB1 expression. These findings potentially provide insight into the pathogenesis of cerebral I/R injury and may also provide a novel direction for the development of therapeutic strategies for this condition. However, there 
are limitations to the present study. First, it was an in vitro study and no in vivo experiments were performed and second, the molecular mechanisms underlying the effects of S100a8 inhibition on BV2 cells function were not fully investigated. These issues require further in-depth investigations and will be addressed in future studies.

\section{Acknowledgements}

Not applicable.

\section{Funding}

No funding was received.

\section{Availability of data and materials}

The datasets used and/or analyzed during the current study are available from the corresponding author on reasonable request.

\section{Authors' contributions}

WH designed the study and wrote the manuscript; CL performed the experiments, collected and analyzed the data. Both authors read and approved the final manuscript.

\section{Ethics approval and consent to participate}

Not applicable.

\section{Patients consent for publication}

Not applicable.

\section{Competing interests}

The authors declare that they have no competing interests.

\section{References}

1. Hayakawa K, Tanda K, Koshino S, Nishimura A, Kizaki Z and Ohno K: Pontine and cerebellar injury in neonatal hypoxic-ischemic encephalopathy: MRI features and clinical outcomes. Acta Radiol: Jan 24, 2020 (Epub ahead of print). doi: $10.1177 / 0284185119900442$.

2. Douglas-Escobar M and Weiss MD: Hypoxic-ischemic encephalopathy: A review for the clinician. JAMA Pediatr 169: 397-403, 2015.

3. Dixon BJ, Reis C, Ho WM, Tang J and Zhang JH: Neuroprotective strategies after neonatal hypoxic ischemic encephalopathy. Int J Mol Sci 16: 22368-22401, 2015.

4. Howlett JA, Northington FJ, Gilmore MM, Tekes A, Huisman TA, Parkinson C, Chung SE, Jennings JM, Jamrogowicz JJ, Larson AC, et al: Cerebrovascular autoregulation and neurologic injury in neonatal hypoxic-ischemic encephalopathy. Pediatr Res 74: 525-535, 2013.

5. Busl KM and Greer DM: Hypoxic-ischemic brain injury: Pathophysiology, neuropathology and mechanisms. NeuroRehabilitation 26: 5-13, 2010.

6. Snyder EJ, Perin J, Chavez-Valdez R, Northington FJ, Lee JK and Tekes A: Head Ultrasound resistive indices are associated with brain injury on diffusion tensor imaging magnetic resonance imaging in neonates with hypoxic-ischemic encephalopathy. J Comput Assist Tomogr 44: 687-691 2020.

7. Solevag AL, Schmolzer GM and Cheung PY: Novel interventions to reduce oxidative-stress related brain injury in neonatal asphyxia. Free Radic Biol Med 142: 113-122, 2019.
8. Rodríguez-Rodríguez A, Egea-Guerrero JJ, Murillo-Cabezas F and Carrillo-Vico A: Oxidative stress in traumatic brain injury. Curr Med Chem 21: 1201-1211, 2014.

9. Kovalčíková A, Gyurászová M, Vavrincová-Yaghi D, Vavrinec P, Tóthová L', Boor P, Šebeková K and Celec P: Oxidative stress in the brain caused by acute kidney injury. Metab Brain Dis 33: 961-967, 2018.

10. Khatri N, Thakur M, Pareek V, Kumar S, Sharma S and Datusalia AK: Oxidative stress: Major threat in traumatic brain injury. CNS Neurol Disord Drug Targets 17: 689-695, 2018.

11. Zonis S, Ljubimov VA, Mahgerefteh M, Pechnick RN, Wawrowsky $\mathrm{K}$ and Chesnokova V: p21Cip restrains hippocampal neurogenesis and protects neuronal progenitors from apoptosis during acute systemic inflammation. Hippocampus 23 : 1383-1394, 2013.

12. Kerkhoff C, Klempt $M$ and Sorg C: Novel insights into structure and function of MRP8 (S100A8) and MRP14 (S100A9). Biochim Biophys Acta 1448: 200-211, 1998

13. Gebhardt C, Nemeth J, Angel P and Hess J: S100A8 and S100A9 in inflammation and cancer. Biochem Pharmacol 72: 1622-1631, 2006.

14. Sun P, Li Q, Zhang Q, Xu L and Han JY: Upregulated expression of S100A8 in mice brain after focal cerebral ischemia reperfusion. World J Emerg Med 4: 210-214, 2013.

15. Dessing MC, Tammaro A, Pulskens WP, Teske GJ, Butter LM, Claessen N, van Eijk M, van der Poll T, Vogl T, Roth J, et al: The calcium-binding protein complex S100A8/A9 has a crucial role in controlling macrophage-mediated renal repair following ischemia/reperfusion. Kidney Int 87: 85-94, 2015.

16. Li Y, Chen B, Yang X, Zhang C, Jiao Y, Li P, Liu Y, Li Z, Qiao B, Bond Lau W, et al: S100a8/a9 signaling causes mitochondrial dysfunction and cardiomyocyte death in response to ischemic/reperfusion injury. Circulation 140: 751-764, 2019.

17. Sakaguchi M, Yamamoto M, Miyai M, Maeda T, Hiruma J, Murata H, Kinoshita R, Winarsa Ruma IM, Putranto EW, Inoue Y, et al: Identification of an S100A8 receptor neuroplastin- $\beta$ and its heterodimer formation with EMMPRIN. J Invest Dermatol 136: 2240-2250, 2016.

18. Zhao J, Yin M, Deng H, Jin FQ, Xu S, Lu Y, Mastrangelo MA, Luo $\mathrm{H}$ and Jin ZG: Cardiac Gab1 deletion leads to dilated cardiomyopathy associated with mitochondrial damage and cardiomyocyte apoptosis. Cell Death Differ 23: 695-706, 2016.

19. Sun L, Chen C, Jiang B, Li Y, Deng Q, Sun M, An X, Yang X, Yang Y, Zhang R, et al: Grb2-associated binder 1 is essential for cardioprotection against ischemia/reperfusion injury. Basic Res Cardiol 109: 420, 2014.

20. Holgado-Madruga M and Wong AJ: Gab1 is an integrator of cell death versus cell survival signals in oxidative stress. Mol Cell Biol 23: 4471-4484, 2003.

21. Lu T, Wang Z, Prativa S, Xu Y, Wang T, Zhang Y, Yu L, $\mathrm{Xu}$ N, Tang J, You W, et al: Macrophage stimulating protein preserves blood brain barrier integrity after intracerebral hemorrhage through recepteur d'origine nantais dependent GAB1/Src/ $\beta$-catenin pathway activation in a mouse model. J Neurochem 148: 114-126, 2019.

22. Li Y, Thompson H, Hemphill C, Hong F, Forrester J, Johnson RH, Zhang W and Meldrum DR: An improved one-tube RT-PCR protocol for analyzing single-cell gene expression in individual mammalian cells. Anal Bioanal Chem 397: 1853-1859, 2010.

23. Rocha-Ferreira E, Vincent A, Bright S, Peebles DM and Hristova M: The duration of hypothermia affects short-term neuroprotection in a mouse model of neonatal hypoxic ischaemic injury. PLoS One 13: e0199890, 2018.

24. Lundgren C, Brudin L, Wanby AS and Blomberg M: Ante- and intrapartum risk factors for neonatal hypoxic ischemic encephalopathy. J Matern Fetal Neonatal Med 31: 1595-1601, 2018.

25. Huang SY, Tai SH, Chang CC, Tu YF, Chang CH and Lee EJ: Magnolol protects against ischemic-reperfusion brain damage following oxygen-glucose deprivation and transient focal cerebral ischemia. Int J Mol Med 41: 2252-2262, 2018.

26. Zhang J, Xiao F, Zhang L, Wang X, Lai X, Shen Y, Zhang M, Zhou B, Lang H, Yu P and Hua F: Alpha-Lipoic acid preconditioning and ischaemic postconditioning synergistically protect rats from cerebral injury induced by ischemia and reperfusion partly via inhibition TLR4/MyD88/NF- $\mathrm{B}$ signaling pathway. Cell Physiol Biochem 51: 1448-1460, 2018.

27. Ma M, Uekawa K, Hasegawa $Y$, Nakagawa T, Katayama $T$, Sueta D, Toyama K, Kataoka K, Koibuchi N, Kuratsu J and Kim-Mitsuyama S: Pretreatment with rosuvastatin protects against focal cerebral ischemia/reperfusion injury in rats through attenuation of oxidative stress and inflammation. Brain Res 1519: 87-94, 2013. 
28. Yu LM, Di WC, Dong X, Li Z, Zhang Y, Xue XD, Xu YL, Zhang J, Xiao X, Han JS, et al: Melatonin protects diabetic heart against ischemia-reperfusion injury, role of membrane receptor-dependent cGMP-PKG activation. Biochim Biophys Acta Mol Basis Dis 1864: 563-578, 2018.

29. Jiang S, Li T, Ji T, Yi W, Yang Z, Wang S, Yang Y and Gu C: AMPK: Potential therapeutic target for ischemic stroke. Theranostics 8: 4535-4551, 2018.

30. Hwang JH, Kumar VR, Kang SY, Jung HW and Park YK: Effects of flower buds extract of tussilago farfara on focal cerebral ischemia in rats and inflammatory response in BV2 microglia. Chin J Integr Med 24: 844-852, 2018.

31. Luo Y, Wang C, Li WH, Liu J, He HH, Long JH, Yang J, Sui X, Wang S, You Z and Wang YA: Madecassoside protects BV2 microglial cells from oxygen-glucose deprivation/reperfusion-induced injury via inhibition of the toll-like receptor 4 signaling pathway. Brain Res 1679: 144-154, 2018.

32. Chen J, Zhang DM, Feng X, Wang J, Qin YY, Zhang T, Huang Q, Sheng R, Chen Z, Li M and Qin ZH: TIGAR inhibits ischemia/reperfusion-induced inflammatory response of astrocytes. Neuropharmacology 131: 377-388, 2018.

33. Li X, Cheng S, Hu H, Zhang X, Xu J, Wang R and Zhang P: Progranulin protects against cerebral ischemia-reperfusion $(\mathrm{I} / \mathrm{R})$ injury by inhibiting necroptosis and oxidative stress. Biochem Biophys Res Commun 521: 569-576, 2020.

34. Ayala A, Munoz MF and Arguelles S: Lipid peroxidation: Production, metabolism, and signaling mechanisms of malondialdehyde and 4-hydroxy-2-nonenal. Oxid Med Cell Longev 2014 360438, 2014.

35. Guo M, Lu H, Qin J, Qu S, Wang W, Guo Y, Liao W, Song M, Chen $\mathrm{J}$ and Wang Y: Biochanin a provides neuroprotection against cerebral ischemia/reperfusion injury by Nrf2-Mediated inhibition of oxidative stress and inflammation signaling pathway in rats. Med Sci Monit 25: 8975-8983, 2019.

36. Cui Y, Wang JQ, Shi XH, Wang YY, Liu HY, Li Z, Dong Y, Mang J and Xu ZX: Nodal mitigates cerebral ischemia-reperfusion injury via inhibiting oxidative stress and inflammation. Eur Rev Med Pharmacol Sci 23: 5923-5933, 2019.

37. Pruenster M, Vogl T, Roth J and Sperandio M: S100A8/A9: From basic science to clinical application. Pharmacol Ther 167: 120-131, 2016.

38. Fujita Y, Khateb A, Li Y, Tinoco R, Zhang T, Bar-Yoseph $\mathrm{H}$ Tam MA, Chowers Y, Sabo E, Gerassy-Vainberg S, et al: Regulation of S100A8 Stability by RNF5 in intestinal epithelial cells determines intestinal inflammation and severity of colitis. Cell Rep 24: 3296-3311.e6, 2018.

39. Ma L, Sun P, Zhang JC, Zhang Q and Yao SL: Proinflammatory effects of S100A8/A9 via TLR4 and RAGE signaling pathways in BV-2 microglial cells. Int J Mol Med 40: 31-38, 2017.

40. Simard JC, Cesaro A, Chapeton-Montes J, Tardif M, Antoine F, Girard D and Tessier PA: S100A8 and S100A9 induce cytokine expression and regulate the NLRP3 inflammasome via ROS-dependent activation of NF-KB(1). PLoS One 8: e72138, 2013.
41. Ren Z, Chen L, Wang Y, Wei X, Zeng S, Zheng Y, Gao C and Liu H: Activation of the Omega-3 Fatty Acid Receptor GPR120 protects against focal cerebral ischemic injury by preventing inflammation and apoptosis in mice. J Immunol 202: 747-759, 2019.

42. Liu H, Wu X, Luo J, Wang X, Guo H, Feng D, Zhao L, Bai H, Song M, Liu X, et al: Pterostilbene attenuates astrocytic inflammation and neuronal oxidative injury after Ischemia-Reperfusion by inhibiting NF-KB phosphorylation. Front Immunol 10: 2408 , 2019.

43. Weng C, Chen Y, Wu Y, Liu X, Mao H, Fang X, Li B, Wang L, Guan M, Liu G, et al: Silencing UBE4B induces nasopharyngeal carcinoma apoptosis through the activation of caspase 3 and $\mathrm{p} 53$. Onco Targets Ther 12: 2553-2561, 2019.

44. He JT, Li HQ, Li GF and Yang L: Hyperoside protects against cerebral ischemia-reperfusion injury by alleviating oxidative stress, inflammation and apoptosis in rats. Biotechnol Biotechnol Equipment 33: 798-806, 2019.

45. Ouyang YB and Giffard RG: MicroRNAs affect BCL-2 family proteins in the setting of cerebral ischemia. Neurochem Int 77: 2-8, 2014.

46. Gupta R and Ghosh S: Putative roles of mitochondrial Voltage-Dependent Anion Channel, Bcl-2 family proteins and c-Jun N-terminal Kinases in ischemic stroke associated apoptosis. Biochim Open 4: 47-55, 2017.

47. Kerkhoff C, Voss A, Scholzen TE, Averill MM, Zänker KS and Bornfeldt KE: Novel insights into the role of S100A8/A9 in skin biology. Exp Dermatol 21: 822-826, 2012.

48. Hu Y, Fan B, Zhang LH, Cheng XJ, Niu ZJ and Ji JF: Clinical significance of S100A8 and S100A9 expression in gastric cancer Zhonghua Yi Xue Za Zhi 93: 3369-3374, 2013 (In Chinese).

49. Ghavami S, Eshragi M, Ande SR, Chazin WJ, Klonisch T, Halayko AJ, McNeill KD, Hashemi M, Kerkhoff C and Los M: S100A8/A9 induces autophagy and apoptosis via ROS-mediated cross-talk between mitochondria and lysosomes that involves BNIP3. Cell Res 20: 314-331, 2010.

50. Jianrong S, Yanjun Z, Chen Y and Jianwen X: DUSP14 rescues cerebral ischemia/reperfusion (IR) injury by reducing inflammation and apoptosis via the activation of Nrf-2. Biochem Biophys Res Commun 509: 713-721, 2019.

51. Hao MQ, Xie LJ, Leng W and Xue RW: Trim47 is a critical regulator of cerebral ischemia-reperfusion injury through regulating apoptosis and inflammation. Biochem Biophys Res Commun 515: 651-657, 2019.

52. Higuchi K, Nakaoka Y, Shioyama W, Arita Y, Hashimoto T, Yasui T, Ikeoka K, Kuroda T, Minami T, Nishida K, et al: Endothelial Gab1 deletion accelerates angiotensin II-dependent vascular inflammation and atherosclerosis in apolipoprotein $\mathrm{E}$ knockout mice. Circ J 76: 2031-2040, 2012.

This work is licensed under a Creative Commons Attribution-NonCommercial-NoDerivatives 4.0 International (CC BY-NC-ND 4.0) License. 